\title{
XI Encontro Nacional de Catálise e Materiais Porosos (XI ENCMP) \& II Reunião do Grupo do Carbono (II RGC) - Online
}

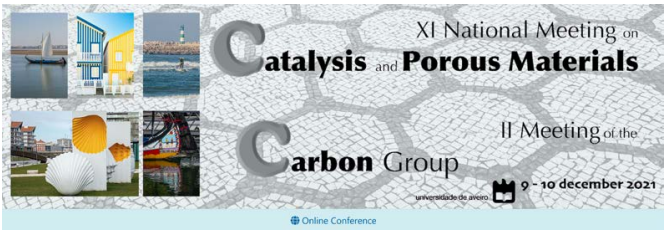

É com grande satisfação que fazemos o convite a juntarem-se a nós no XI Encontro Nacional de Catálise e Materiais Porosos (XI ENCMP) e na II Reunião do Grupo do Carbono (II RGC).

Pela primeira vez, as comunidades da Divisão de Catálise e Materiais Porosos (DCMP) e do Grupo do Carbono (GC) estarão reunidas no mesmo evento, proporcionando uma esplêndida oportunidade para os cientistas da academia e da indústria partilharem e discutirem os progressos científicos mais recentes e iniciarem ou aprofundarem colaborações interdisciplinares em catálise, química, materiais, energia, biologia, ou outras áreas.

Convidamos todos os autores presentes no XI ENCMP e na II RGC a enviarem manuscritos baseados nos temas científicos abordados nas apresentações orais e em painel para publicação no QuímICA (b-quimica.spq.pt).

Pela Comissão Organizadora,

Mário M. Q. Simões (UA) \& Anabela A. Valente (UA)

Mais informações em

xiencmp-iirgc.events.chemistry.pt

\section{chemistry
Europe FELLOWS Europe Fellows 2020/2021}

O Programa Chemistry Europe Fellows foi criado em 2015 pelos presidentes e representantes da Chemistry Europe para reconhecer a contribuição e serviço dos membros das sociedades da Chemistry Europe. 0 Chemistry Europe Fellows foi criado para promover a identidade da Chemistry Europe dentro da Europa continental, mas não se limita a este continente, sendo a maior homenagem concedida por esta entidade. Os Fellows recebem um certificado e mantêm a designação de Chemistry Fellow para sempre.

As candidaturas para 2020/2021 devem ser enviadas para a Dr. ${ }^{a}$ Vera Koester, Secretária-Geral do Programa Chemistry Europe Fellows, até 3 de dezembro de 2021. A divulgação dos eleitos será efetuada durante a primavera de 2022.

Mais informações em

chemistryviews.org/view/fellows

\section{Nomeações para Prémios EuChemS 2021}

Estão abertas as nomeações para os seguintes prémios EuChems:

2021 EuChemS Lecture Award

2021 EuChemS Award for Service

2021 EuChemS Historical Landmarks Award

Members of the International Award Committee for the European Chemistry Gold Medal (IACM)

As nomeações para 2021 podem ser submetidas através de um formulário online até sexta-feira, 31 de dezembro de 2021, às 18:00 CET.

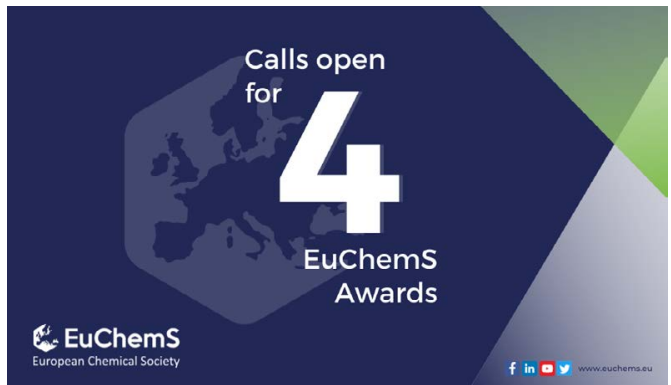

Mais informações em: euchems.eu/calls-open-awards 